\title{
Possibility and persistence of educational change research: Concluding remarks to the twentieth anniversary issue of the Journal of Educational Change
}

\author{
Corrie Stone-Johnson ${ }^{1}$
}

Published online: 21 July 2020

(c) Springer Nature B.V. 2020

Dennis Shirley's introductory remarks to this Special Issue of the Journal of Educational Change and all of the articles presented here are a powerful reminder of everything this journal has tried — and arguably succeeded — to be over the last 20 years. The Journal has served a valuable role in the educational research community since its inception. In addition to being a venue for international researchers to explore the shifting terrain of educational change in their own contexts and in places far away, the Journal has taken pride in encouraging the heterodox views inherent within the field.

The articles herein embody the vitality of our field. Vectors of disagreement demonstrate that the change process is messy, contested, and complicated but also full of promise, momentum, and force. There is a danger in a type of "both-sides-ism" that can imperil a field, watering down what is published to a pablum that inspires no one. The articles in this issue - and in the twenty past years of the Journal - are in no such danger. These articles take a stance, urging us to be better researchers and citizens of the world.

Take the vector of professionalism, for example. Who determines what professionalism is? Does everyone experience it the same way? Over the last decade I have described how different generations of teachers experience accountability broadly and professionalism specifically, underscoring that what one generation finds constricting another often finds helpful (Stone-Johnson 2011, 2014, 2016). Within this vector I considered what I termed "parallel professionalism": (2017)—the notion that different generations of teachers can experience a phenomenon simultaneously yet differently. This collection of articles does something similar, showing how phenomena such as professionalism, taking change to scale, and educating for justice are all agreed upon as important but not are experienced by educators in the same way.

Corrie Stone-Johnson

corriest@buffalo.edu

1 University at Buffalo, Buffalo, USA 
Even as we have encouraged and even sought out research across these vectors of disagreement, research within the field of educational change remains stubbornly bound to what Tyack and Tobin (1994) refer to as the "grammar of schooling". This turn of phrase is among the most frequently used within our field, and for good reason; it encapsulates how we understand school and why it remains so challenging to make it fundamentally any different than it has nearly always been. Across nearly all of the regions of the world covered in this journal, school looks nearly identical. Thus, while the views presented within these pages may be heterodox, there is a certain stubbornness to the structural orthodoxy of school.

This tension-between the possibility of change and the persistence of the grammar of schooling-summarizes much of the scholarship in our field as well as the articles in this Special Issue. Even so, while there is space within the vectors of disagreement, there has generally been little consideration of new or alternative grammars. Recent scholarship outside (Mehta and Fine 2019) and within this journal (Courtney and Mann in press) has begun to explore such alternative grammars or lexicons. Mehta and Fine (2019), for example, envision the expansion of places where students learn from just schools to places in addition to schools, such as community centers and even online (p. 380). They also identify different grammars operating within traditional schools, in some of the electives that students take or in their choice of extracurricular activities. Differently, yet also importantly, Courtney and Mann suggest that what both Tyack and Tobin, and Mehta and Fine call "grammars" actually reflect but do not define grammars. Courtney and Mann reconceptualize the grammar of schooling to be the ideology that orients institutions within a given period. By this view, grammars are not the structures or actions within them but rather the international discourses of industrialization, welfarism, neoliberalism, and neoconservatism that shape what goes on in schools.

Though these conversations about the grammar of schooling offer a new lens by which to understand the organization of educational work, I would argue that they also do not fundamentally challenge it. Valuing more places where young people learn is necessary - and Mehta and Fine's work opens a space for centering work that does so for students who traditionally do not benefit from the more innovative features generally saved for the more privileged—but the original grammar persists. Likewise, the ways that Courtney and Mann reconceptualize what we call grammar is helpful in shifting our gaze from structures to ideologies, but what they call the lexical features of the grammar - the structures of schooling-by and large remain.

I bring up the grammar of schooling not to critique our field's work but rather to position it within the current context of COVID-19. The year 2020 brought with it a playful opportunity to look back over the last 20 years and chart a path forward for the next twenty. Dennis Shirley and I proposed a Special Issue for this purpose and invited authors to consider the last two decades of research on educational change and suggest directions for the Journal going forward. We asked authors to write these pieces in 2019 with the plan to publish the article in 2020. At the same time, we intended for this Special Issue to mark an editorial shift to my own new role.

What we did not plan for was COVID-19. As we put the finishing touches on our introductory and concluding remarks - from our homes, socially distant-in June 2020, we cannot help but feel that this Special Issue serves as a time capsule not just 
of the accumulated knowledge of educational change since the turn of the twentyfirst century but of the very idea of school itself, a collection of ideas preserved in amber to recall what educational life was like "before." In this moment of worldwide chaos, and especially in this moment of massive shifts in both school as a physical structure and schooling as a more global concept, we are forced to re-consider our original reflective intent and to shift from a musing on what it has meant to study educational change to chart a new course for what it should mean. It is within this reconsideration that we have the potential to challenge the grammar of schooling. We have the opportunity to remake schools that are more equitable for more people, more professional for those who work in them and more inclusive for those who depend on them. Even using grammar as a term of discourse, we are most certainly heading into a new grammar that is yet to be defined. As researchers in the field of educational change, we have the opportunity to shape this discourse, and future issues of the Journal of Educational Change will take a central role in doing so.

The COVID-19 pandemic has revealed that for too many students around the world, school is their only safe harbor, their only source of food and health care, their primary connection to the internet, their sole connection to their friends and teachers. The implications for equity feel insurmountable given the scope of the pandemic. What is the right thing to do in this moment?

Principles of do no harm abound. Some schools are taking the approach that if not everyone can access the curriculum, no one should, and traditional instruction has ceased. Some schools are taking the approach that no student can do any worse than they were doing prior to school closure; students can advance but cannot fall behind in their grades. Numerous non-profits are generating a tsunami of on-line resources for free-but they cannot guarantee that these are accessed by the students most needful of them. All responses try to approach equity, but none succeed fully.

At this moment, there are questions about how schools can recover from the setbacks experienced in these last few months. Certainly, many researchers will respond to these questions. But for readers and scholars of educational change and our Journal, I would like to suggest that we ask a different question, one that builds on the three vectors of disagreement outlined by Dennis and offers a path toward agreement: What weaknesses in educational change research do these vectors reveal, how has COVID-19 brought these weaknesses into even starker contrast, and how can we as a field respond in ways that improve school and schooling around the world while also making our field more robust, more relevant, and more far-reaching? Have we been asking questions that helped only ourselves, keeping the research in language that was inaccessible or even unavailable to people in schools? Was our focus on a few countries too narrow? Were our voices too few? Too privileged? Several articles in this issue would respond affirmatively. Our conversations in educational change have primarily been with each other, limited to our too narrow group of thinkers. We have failed, or at least not done enough, to make space for people doing the work in schools.

The timing of this Special Issue coincides with a momentous opportunity to reconsider our work as scholars. Many of the top researchers not just in educational change but in educational research more broadly have opined on the impact these seismic shifts will have for schools. There are undoubtedly issues of equity, 
of access, of instructional quality, of teachers' autonomy and professionalism, and of the sheer physicality of what ideal schools can and should look like. I would like to use this space to consider a different angle: What role can the Journal of Educational Change play in not only responding to but envisioning how educational change research should look, going forward? As Counts (2013) famously asked: Dare the schools build a new social order?

Once again, we have the opportunity to address this challenge. Does our Journal dare to take on the most pressing and vexing questions? Does our Journal dare invite new voices into the fold? Does our Journal dare reconsider change scholarship writ large? Can we at last write a new grammar of school that breaks the mold that has persisted for so long? Indeed, these very questions of educational change have never been more opportune. For the last 20 years, it has been a hypothetical question: How can we take what exists and make it better for more people? Going forward, we have an even more powerful platform: given our expertise about what is needed for school change, and our many years of extensive research from around the world, what role can we, as researchers, take in helping our partners in the field shape their future? And what can we learn from them as they do so?

This Special Issue in a sense marks the beginning of defining this role for our journal. Likewise, the shift in editorship of this esteemed journal brings with it a new opportunity to define a vision for the future. With the publication of this Special Issue, I assure you that an incredible amount of progress and promise exists in spite of the persistence of the grammar of schooling. Teaching and leading schools can and should be more equitable, more professional, more inclusive, more global. Schools are becoming community support systems for the most vulnerable students and families. Teachers' work is becoming more respected and valued. Collectively, these are positive signs that educational change_-real, true, sustainable educational change-was happening.

In the spirit of progress and promise as well as continuous learning-and at a time when the uncertainty of schools looms large-I invite you, members of our educational change community, to dare with me. I ask you to think about how our role as researchers and scholars around the world could do things differently.

Please do not mistake my request as an opportunistic use of a devastating circumstance; I am not asking that we capitalize on what has been lost for our own gain. Rather, I am suggesting that now more than ever we have a chance to be at the table with educators as they try to make sense of the changed world. There is no precedent for what is happening and we have none of our traditional trappings to work from; we have no evidence of best practice, no randomized control trials to say what does or does not work. But we do have the collective wisdom of the last 20 years to make sure that what we know works-collective thinking, reflective practice, creative instruction, professional treatment, an eye toward justice-should not be lost. At the same time, our colleagues in schools also know what works-they do the work day in and day out. Let's join together to build a new type of educational change research-collaborative, practice-focused, evidence-informed, critically considered, multi-national, truly just research that welcomes all voices. Together, we can be a part of sustainable educational change for the next generation of students, teachers, and school leaders. 


\section{References}

Counts, G. S. (2013). Dare the school build a new social order? In D. J. Flinders \& S. J. Thornton (Eds.), Curriculum studies reader (pp. 59-66). London: Routledge.

Courtney, S. (in press). Thinking with 'lexical' features to reconceptualize the 'grammar' of schooling: Shifting the unit of analysis from school to society. Journal of Educational Change.

Mehta, J., \& Fine, S. (2019). In search of deeper learning: The quest to remake the American high school. Cambridge: Harvard University Press.

Stone-Johnson, C. (2011). Talkin' bout my generation: Boomers, Xers, and educational change. Journal of Educational Change, 12(2), 221-239.

Stone-Johnson, C. (2014). Parallel professionalism in an era of standardisation. Teachers and Teaching: Theory and Practice, 20(1), 74-91.

Stone-Johnson, C. (2016). Generational identity, educational change, and school leadership. London: Routledge.

Stone-Johnson, C. (2017). Autonomy, professionalism, and the role of generation in professional capital. Journal of Professional Capital and Community, 2(1), 18-35.

Tyack, D., \& Tobin, W. (1994). The "grammar" of schooling: Why has it been so hard to change? American Educational Research Journal, 31(3), 453-479.

Publisher's Note Springer Nature remains neutral with regard to jurisdictional claims in published maps and institutional affiliations. 